\title{
Subtleties of the sonic
}

\section{Douglas Repetto explores the multilayered aesthetic of sound as art at New York's Museum of Modern Art.}

$\mathrm{S}$ everal years ago, a colleague noted similarities between the visualizations appearing on his computer screen when he played Beethoven, and graphs of the timeseries data he was recording in his lab from cancer cells and sleeping human brains. Could he play back his data as sound, he asked? Yes: with some clever bit twiddling, you can turn any digital data source into sound, because a digital sound recording is simply a series of numbers. But is it music?

Entrenched controversies surround both the definition of music and the core relationships between sound, music and human perception. The bleeps and buzzes of bioelectrical recordings may sound nothing like Beethoven, but they would not be out of place on a dance-music track, and their structures can be similar to musical forms. Given the ambiguities, many artists working
Soundings: A

Contemporary Score

Museum of Modern Art, New York City. Until 3 November 2013.

with sound avoid the term 'music' and call themselves sound artists, or simply artists. A wonderful collection of sound-oriented works by 16 mostly young artists is currently on display at New York's Museum of Modern Art. Soundings: A Contemporary Score is the first group show in the museum's history to focus on sound as artistic expression.

Soundings challenges the idea that listening is all about the ears. The rise of recording and playback technologies has left many thinking of sound (from music and audio books to rainforest-relaxation mixes) as best experienced in private through noise-cancelling headphones. But until about a hundred years ago, all sound was environmental: its source was nearby and an individual's experience of it was driven by its social and environmental context. The works in the exhibition entirely dispense with the concept of private, ear-centric listening. Sergei Tcherepnin's Motor-Matter Bench (2013), for example, is rump-centric: a New York City subway bench has been wired up as a large speaker, with the heavy wooden seats filtering the sound. Sit on the bench and Tcherepnin's composition is transmitted through your bottom.

Nearby, Camille Norment's Triplight (2008), pictured, is completely silent: a flickering light inside the hollowed-out shell of an antique microphone casts a beguiling ribcage shadow on the walls, evocative of a smoky jazz club. That such a simple visual gesture can evoke a complex, multimodal scene is not surprising, given the tangled connections between our senses, 
perceptions and memories.

Some artists work directly with sound as a physical material, finding ways to alternately elucidate and confound our physical and perceptual understanding of sonic phenomena. In wellenwanne lfo (2012), Carsten Nicolai plays inaudible, low-frequency sounds through four small transducers resting in a shallow trough of water. The rippled interference patterns are reflected by a mirror and presented in an upright, framelike light box - inaudible sound as a gently undulating abstract photograph.

Tristan Perich's monumental Microtonal Wall (2011) is certainly audible, and what you hear is both exhilarating and deeply confusing. A grid of 1,500 small speakers is mounted in an aluminium frame along a hallway. Each speaker plays a fixed frequency, arranged low to high from the bottom-left to top-right of the grid. The tones span four octaves, and, as expected, the effect of such dense sound is almost white noise. But if you get an ear close enough (and everyone does), you suddenly discover a world of rich physical and psychoacoustic effects: endless microglissandi, wild acoustic beating and bewildering spatial movements. Our wet brains and the messy physical world quickly turn a clean, precise stimulus into a riot of perception.

Christine Sun Kim's soundless works on paper play with the translation of sound and language concepts into visual marks. In Scores and Transcripts (2012), she presents a set of playful but poignant drawn interpretations of American Sign Language phrases and musical dynamics. From a distance, the red swoop of All. Night. (2012) reads as a giant cartoon chin. Pianoiss ... issmo (Worse Finish) (2012) is a classic bifurcation diagram rendered with tiny pianissimo marks. Deaf since birth, Kim's seemingly offhand drawing style belies a rich understanding of the mostly unconscious ways in which sound mediates physical and social relationships in the hearing world.

Jana Winderen takes a literal approach to translating sounds between worlds in her 16-speaker installation Ultrafield (2013). She recorded the ultrasonic clicks, whistles and whirrs of insects, fish and bats, and then digitally shifted their frequencies down into the range of human hearing before mixing them into a densely layered, half-familiar, half-exotic sound world. It's the sound of a science-fiction superhighway running through a shrieking, burbling rainforest. Or maybe the sound of a human brain, struggling to make sense of itself as a species that enjoys shrilling insects and string trios in equal measure.

Douglas Repetto is an artist, teacher and director of the Sound Art MFA programme at Columbia University in New York. e-mail:dr501@columbia.edu

\section{Books in brief}

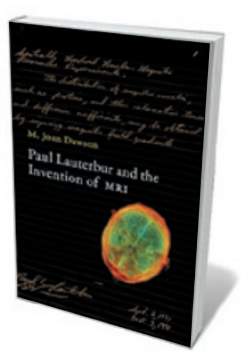

Paul Lauterbur and the Invention of MRI

M. Joan Dawson MIT PRESS (2013)

As light-bulb moments go, Paul Lauterbur's was one of the quirkier. On 2 September 1971, the chemist was eating a hamburger when he realized that images could be derived from nuclear magnetic resonance signals, then used to detect tumours in tissue samples. The discovery paved the way for magnetic resonance imaging, which allows diagnosis of a multitude of conditions without the need for ionizing radiation. Molecular biologist Joan Dawson, Lauterbur's widow, deftly interweaves biography and breakthroughs with the findings of others in the field, such as Raymond Damadian.

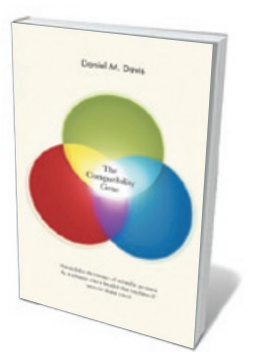

\section{The Compatibility Gene}

Daniel M. Davis AlLEN LANE (2013)

Eminent immunologist Daniel Davis tells the story of the "molecular mark that distinguishes each of us as individuals". The genes of the major histocompatibility complex (MHC) are big players in the immune system, and are implicated in conditions from ankylosing spondylitis to multiple sclerosis. Starting with the work of Peter Medawar and Peter Gorer on immunology, transplantation and the $\mathrm{MHC}$, Davis ranges energetically through the research. Cultural references and anecdotes abound, but the book's shifts in tone between breezy and technical may unsettle some.

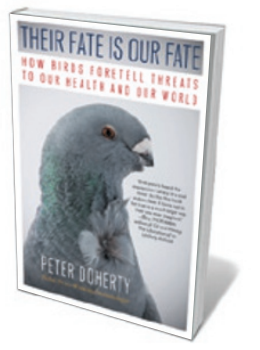

\section{Their Fate is Our Fate: How Birds Foretell Threats to Our Health} and Our World

Peter Doherty THE EXPERIMENT (2013)

Like billions of coal-mine canaries, avian species tell us much about environmental crises, Nobel-prizewinning immunologist Peter Doherty reminds us. He explores how birds reflect the progress of epidemics and environmental change, framed by his own adventures in disease ecology. From 'sentinel chickens' - used to monitor the spread of arbovirus - to the migratory red knot Calidris canutus rufa, whose decline points to trouble down the food chain, Doherty flies with us through key vistas of science.

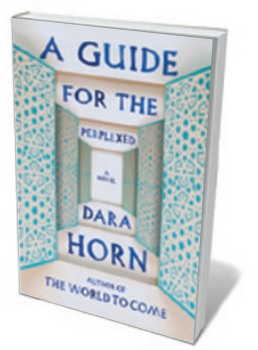

\section{A Guide for the Perplexed: A Novel}

Dara Horn W. W. NORTON (2013)

Computer science and medieval philosophy mesh in Dara Horn's accomplished novel about digital dangers and the nature of memory. Software supremo Josie Ashkenazi's program Genizah (Hebrew for 'repository of sacred texts') creates palaces of memory housing images and documents. In post-Arab Spring Cairo, she is brutally kidnapped. That headlong narrative is woven through with the real-life stories of scholar Solomon Schechter, who discovered a famous genizah in Cairo, and twelfth-century Jewish philosopher Moses Maimonedes, whose treatise gives the novel its name.

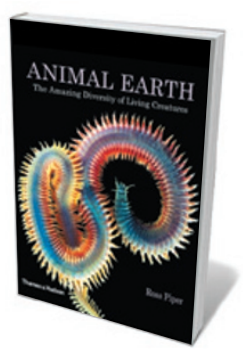

Animal Earth: The Amazing Diversity of Living Creatures Ross Piper THAMES AND HUDSON (2013)

In a seabed near you may lurk Tubiluchus priapulids - penis worms resembling shower heads with tails. Zoologist Ross Piper presents a parade of charismatic yet overlooked fauna in this sumptuous volume. The bioluminescent comb jelly Beroe abyssicola - not unlike a glowing papaya - and the candy-coloured twists of annelid worm Alitta virens are astounding enough. But the Persian carpet flatworm Pseudobiceros bedfordi is an aesthete's delight, sporting a black-and-scarlet pattern straight out of haute couture. Barbara Kiser 